\title{
CAPITALISMO E EQUILÍBRIO ECOLÓGICO: UMA IMPOSSIBILIDADE HISTÓRICA
}

\author{
CAPITALISM AND ECOLOGICAL BALANCE: A \\ HISTORICAL IMPOSSIBILITY
}

José Antonio Dias ${ }^{1}$

Professor de geografia da rede Pública municipal de Lages-SC; Mestrando em Educação pelo Programa de Pós-Graduação em Educação da Universidade do Planalto Catarinense, Lages, Santa Catarina, Brasil. E-mail: joseantoniodias@uniplaclages.edu.br.

Geraldo Augusto Locks² Professor do Programa de PósGraduação, Mestrado em Educação da Universidade do Planalto Catarinense, Lages, Santa Catarina, Brasil. E-mail:

prof.geraldo@uniplaclages.edu.br

\section{RESUMO}

Os problemas ecológicos, há algum tempo, não podem ser ignorados. As consequências da degradação ambiental se revelam por todo o mundo e medidas para reduzir o impacto do ser humano já são fomentadas, mas frustradas. Entretanto, como é demonstrado pelos excertos de notícias trazidas para esta pesquisa qualitativa, a destruição dos espaços naturais é determinada pelo modo de produção capitalista hegemônico, que em seu desenvolvimento histórico, insiste em avançar sobre os bens naturais. Nesse sentido, a pandemia do Coronavírus, mesmo sendo aparentemente um elemento natural, é exemplar produto da natureza trabalhada pelo ser humano. Assim, através de um referencial bibliográfico com base no materialismo histórico-dialético, neste trabalho é apontado algumas contradições que demonstram a impossibilidade de uma relação do ser humano com a natureza que não comprometa a qualidade da vida no planeta sem a superação do modo de produção capitalista. Pois, as consequências da destruição ecológica são transformadas em oportunidades de mais lucro, não sendo, portanto, um problema para a reprodução e aprofundamento das contradições desta forma de organização econômica e social.

PALAVRAS-CHAVE: Ecologia, Capitalismo, Trabalho.

\section{ABSTRACT}

Ecological problems for some time cannot be ignored. The consequences of environmental degradation are revealed all over the world and measures to reduce the impact of human beings are already fostered but frustrated. However, as demonstrated by the excerpts of news brought to this qualitative research, the destruction of natural spaces is determined by the hegemonic capitalist mode of production, which in its historical development insists on advancing on natural goods. In this sense, the Coronavirus pandemic, even though it is apparently a natural element, is an exemplary product of nature laboured by human beings. Thus, through a bibliographic reference based on historical-dialectical materialism, this search points out some contradictions that demonstrate the impossibility of a relationship between the human being and nature that does not compromise the quality of life on the planet without overcoming the capitalist mode of production. For the consequences of ecological destruction are transformed into opportunities for more profit, and therefore not a problem for the 
reproduction and deepening of the contradictions of this form of economic and social organization.

KEYWORDS: Ecology, Capitalism, Labour.

\section{INTRODUÇÃO}

Vivemos em um momento histórico em que a ecologia novamente interpela a consciência coletiva sobre os cuidados com nosso planeta. As consequências das ações humanas já não aparecem como uma terrível possibilidade num futuro a médio prazo. Mas se revelam no presente através da potencialização de eventos climáticos, que em grande medida castigam os mais empobrecidos. É necessário então analisarmos a construção histórica que produziu esta situação.

Desde a década de 1970 (HARVEY, 2016), muitas medidas para dar conta desta problemática são realizadas por consórcios de nações, como conferencias, documentos, protocolos, cartas, são elaboradas, discutidas e até aplicadas. Entretanto, são paliativos, pois não se enfrenta a origem do processo de degradação irrefreável do planeta, o modo de produção capitalista hegemônico. Indo de encontro às propostas reformistas, esta pesquisa se justifica por apresentar uma breve exposição da problemática que consiste em querer resolver a destruição ambiental sem enfrentar este modo de produção.

Para tanto, tem como objetivo expor elementos que demonstram a impossibilidade de se produzir uma nova forma de convivência do ser humano com a natureza sem superar a lógica do capital, ou seja, a exploração e a acumulação sem considerar a esgotabilidade dos bens disponíveis pela natureza.

\section{METODOLOGIA}

Este trabalho se caracteriza como uma pesquisa qualitativa bibliográfica exploratória (TRIVIÑOS, 1987), usando de livros e de busca de notícias em portais da internet que teve como critério de escolha estar entre os primeiros resultados da busca e que sejam de veículos de matrizes ideológicas diferentes. Para a análise e discussão das informações, o materialismo histórico-dialético é o método utilizado, com base em sua capacidade de relacionar o objeto particular com a totalidade (NETTO, 2015).

\section{RESULTADOS}

É trazida para esta seção excertos de reportagens tratando de processos de degradação ambiental, da pandemia do Coronavírus e da questão da desigualdade social, em especial à posse da terra. 
TABELA 1: Trechos de notícias sobre problemas ambientais e desigualdade social

\begin{tabular}{|c|c|}
\hline TRECHOS DAS NOTICIAS & FONTE \\
\hline $\begin{array}{l}\text { 70\% do desmatamento na América Latina é originado do agroneǵócio para a exportaçăo, o que nâo contribui para a } \\
\text { segurança alimentar das populaçôes dessa regià̃. }\end{array}$ & $\begin{array}{l}\text { ONU para a } \\
\text { Alimentaçăo e a } \\
\text { Agricultura }\end{array}$ \\
\hline $\begin{array}{l}\text { [... Jo Atlas do Agronegócio: fatos e números sobre as corporaçóes que controlam o que comemos traz uma coletánea de } \\
\text { artigos e infográficos que abordam a concentraçăo do setor agricola, agrotóxicos, qualidade do alimento, confitos no } \\
\text { campo, lobby do agronegócio e agroecologial... I; apontou que a América Latina possui a pior distribuiçăo de terras em } \\
\text { todo o mundo: } 51,19 \% \text { das terras agrícolas estäo nas mãos de apenas } 1 \% \text { dos proprietários rurais. O Brasil ocupa o quinto } \\
\text { lugar no ranking de desigualdade no acesso à terra. }\end{array}$ & $\begin{array}{l}\text { Alexandre Guerra para a } \\
\text { Fundação Perseu Abramo }\end{array}$ \\
\hline $\begin{array}{l}\text { Largamente utilizado por grandes pecuaristas para abrir pasto e áreas de plantaçấ de soja o método de colocar fogo } \\
\text { em área verde se transforma em uma das piores alternativas para o meio-ambiente, além de atingir em cheio a imagem } \\
\text { do agronegácio brasileiro em pleno periodo de crize mundial. } \\
\mathrm{Na} \text { Amazônia foram detectados neste ano } 62.627 \text { focos de calor, } 10 \% \text { a mais do que no mesmo periodo do ano paszado } \\
\text { e um recorde desde } 2010 \text {, em uma das análises feita pelo Inpe. O Pantanal apresenta um crescimento de } 210 \% \text { nos focos } \\
\text { de calor, se comparado a mesmo perído de } 2019 \text {. A regiäo registrou } 14.489 \text { focos de calor este ano, contra } 4.660 \mathrm{em} \\
2019 \text {. }\end{array}$ & Midia Ninja \\
\hline 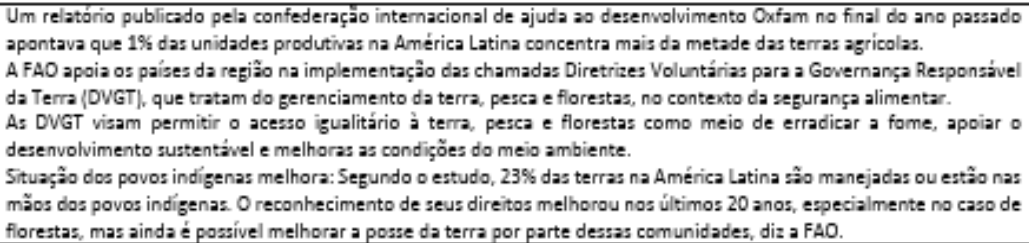 & $\begin{array}{l}\text { Organizaçăo das Naçôes } \\
\text { Unidas para a } \\
\text { Alimentaçăo e a } \\
\text { Agricultura reproduzida } \\
\text { pelo site Terra. }\end{array}$ \\
\hline $\begin{array}{l}\text { O nowo coronavíns se alastrou pelo mundo graças a aç̃o destrutiva e invasora do ser humano contra a natureza, afirma } \\
\text { o pesquizador Allan Carlos Pscheidt, doutor em Biodiversidade Vegetal e Meio Ambiente e professor das faculdades }\end{array}$ & $\begin{array}{l}\text { Entrevista feito ao portal } \\
\text { Brazil e Fato por Erick }\end{array}$ \\
\hline 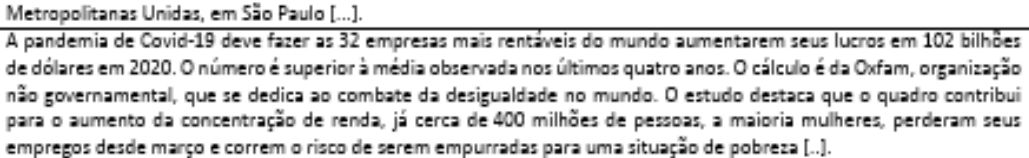 & \begin{tabular}{|l|} 
Gimenes \\
Portal da revista Veja
\end{tabular} \\
\hline
\end{tabular}

Fonte: Elaborado pelos autores

\section{DISCUSSÃO}

A O que nos diferencia, em essência, dos outros animais é a necessidade de produzirmos a nossa própria existência. Para tanto, o ser humano produz a sua existência a partir de uma relação metabólica com a natureza através do trabalho. Desde o cultivo de um vegetal até a mais moderna rede de comunicação possui sua gênese na apropriação e transformação que fizemos dos recursos naturais pelo trabalho (QUAINI, 2002; MARX, 2013; SANTOS, 2014; HARVEY, 2016).

A partir da hegemonia do modo de produção capitalista, no qual a mercantilização se constitui a sobredeterminação de toda organização socioeconômica, há uma subversão do valor dos produtos. Para compreender este fato é preciso explicar que uma mercadoria possui uma dupla dimensão. A primeira corresponde ao valor de uso, que se refere a sua qualidade, ou seja, a característica que torna esse produto necessário ao ser humano. E a segunda, que é o valor de troca, a parte quantitativa da mercadoria, que diz respeito à quantidade de trabalho socialmente necessário para se produzir determinada mercadoria, valor este que só se realiza na troca por um equivalente social de valor, o dinheiro (MARX, 2013).

Com a apropriação dos meios de produção por parte de uma pequena parcela da população, os capitalistas, o processo produtivo só se inicia para a realização 
do valor de troca da mercadoria, invertendo a ordem que existia anteriormente, na qual era o valor de uso que determinava a produção.

Isso significa que o trabalho está subsumido, determinado, pela vontade dos capitalistas em reproduzir o valor (dinheiro) empregado em meios de produção e força de trabalho. Portanto, a própria satisfação das necessidades (seja do estômago ou da fantasia) se subordina à valorização do valor. Como consequência, a relação com a natureza mediada pelo trabalho também é mercantilizada.

Deve-se marcar que a alienação derivada da ascensão da burguesia em seu contexto histórico, produziu uma dicotomização da relação entre o ser humano e a natureza (MOREIRA, 2019). Pondo-nos como sujeitos externos à natureza, que para garantir a sobrevivência é necessário lutar contra ela, restando seu uso enquanto fonte de recursos para a produção de mercadorias.

Mas o capitalismo em sua dinâmica produz as contradições que o condiciona como um sistema de crises. E dentre essas contradições, a do crescimento exponencial infinito atinge diretamente a questão ecológica. Pois o permanente aumento do capital (Valor) está diretamente determinado pela produção e consumo de novas mercadorias em uma escala cada vez maior. O que leva a uma exploração cada vez maior dos recursos naturais (HARVEY, 2016).

Com a mundialização do sistema capitalista, é praticamente impossível a existência de espaços naturais que não apresentem a presença direta ou indireta humana (SANTOS, 2014). Como o exemplo trazido na Tabela 1, o agronegócio exportador é o principal responsável pelo desmatamento e pelas queimadas na região amazônica. Verifica-se também nesses excertos a enorme concentração da terra. Ou seja, a propriedade privada da terra destrói o valor de uso que poderia beneficiar toda a humanidade.

Na mesma tabela, é explicitado a condicionalidade do surgimento da pandemia de Covid-19 pelo o modo de produção hegemônico e que, apesar de o vírus ser aparentemente um elemento natural, ele é produto da natureza trabalhada pelo ser humano. Assim, a sua existência é determinada pelo modo como produzimos a nossa existência.

Percebe-se também que, a médio prazo, a degradação ecológica não é um impeditivo para reprodução do capital, o que coloca em cheque o discurso que a deterioração dos recursos naturais seria um freio para o capital. Para além disso, muitas das tecnologias apresentadas para a solução pontual de problemas ecológicos existem como novas forma de gerar lucro (HARVEY, 2016).

É importante ressaltar que a terra e a natureza em si não possuem valor intrínseco, é a sua metabolização pelo trabalho que se produz mercadorias, e, portanto, o Valor (MARX, 2013). A primazia do valor de troca sobre o valor de uso se desdobra em duas grandes consequências problemáticas: $O$ fato de a natureza em si não produzir valor e sem a compreensão do ser humano como constituinte da mesma, faz com que a ideia de preservação ou sustentabilidade ecológica não passe de um discurso que não se efetiva na realidade (SANTOS, 2012; HARVEY 2016). O outro problema é o não atendimento das necessidades da população, pois o resultado do trabalho sobre a natureza é mercantilizado. Dessa forma, não garantindo uma qualidade de vida digna a todos, algo que seria possível com o nível de produtividade contemporâneo, o sistema do capital afirma o mundo da distopia e nega a superação do reino da necessidade para o reino da liberdade (MARX, 2017). 


\section{CONSIDERAÇÕES FINAIS}

Em que se pese a sua incipiência, esta pesquisa aponta para algumas contradições que se encontram na relação do ser humano com a natureza mediada pelo trabalho no modo de produção capitalista. A tendência de crescimentos exponencial infinito do capital se contrapõe às limitações da natureza enquanto fonte de recursos. De toda forma, em que se considere algumas ações políticas em direção à redução dos danos ecológicos, não é possível uma relação equilibrada entre o ser humano e a natureza sem a superação do sistema do capital.

\section{REFERÊNCIAS}

América Latina tem pior distribuição de terras do mundo, diz FAO. 2017. Disponível em: https://www.terra.com.br/noticias/america-latina-tem-piordistribuicao-de-terras-do-mundo-diz-

fao,b2870bd46b475cc0eb8dc9682d7cc7dafhlljrso.html. Acesso em: 24 mar. 2021.

FAO, Organização das Nações Unidas para a alimentação e a agricultura. FAO: Agronegócio foi responsável por quase $70 \%$ do desmatamento na América Latina. $2016 . \quad$ Disponível em: http://www.fao.org/americas/noticias/ver/pt/c/425810/. Acesso em: 24 mar. 2021.

FERRAZ, Ricardo. Pandemia aumenta lucro de grandes empresas, diz levantamento. 2020. Para a revista Veja. Disponível em: https://veja.abril.com.br/economia/pandemia-aumenta-lucro-de-grandesempresas-diz-levantamento/. Acesso em: 24 mar. 2021.

GIMENES, Erick. Ação humana contra o meio ambiente causou a pandemia do coronavírus, diz pesquisador. 2020. Para o Brasil de Fato. Disponível em: https://www.brasildefato.com.br/2020/03/18/acao-humana-contra-o-meioambiente-causou-a-pandemia-do-coronavirus-diz-pesquisador. Acesso em: 24 mar. 2021.

GUERRA, Alexandre. Concentração de terras na América Latina é a pior do mundo. 2018. Fundação Perseu Abramo. Disponível em: https://fpabramo.org.br/2018/09/12/concentracao-de-terra-no-brasil-e-pior-domundo/. Acesso em: 24 mar. 2021.

HARVEY, David. 17 contradições e o fim do capitalismo. 1 ed. - São Paulo: Editora Boitempo, 2016.

MARX, Karl. O Capital - Crítica da economia política: livro I - o processo de produção do capital. São Paulo - SP: Boitempo, 2013. 751 p. Tradução: Rubens Enderle.

MARX, Karl. O Capital - Crítica da economia política: livro III - o processo global de produção do capitalista; Edição de Friedrich Engels. São Paulo - SP: Boitempo, 2017. 751 p. Tradução: Rubens Enderle. 
MÍDIA NINJA. Qual a relação do agronegócio com as queimadas? 2020. Disponível em: https://midianinja.org/news/qual-a-relacao-do-agronegocio-comas-queimadas/. Acesso em: 24 mar. 2021.

MOREIRA, Ruy. Pensar e ser em geografia. São Paulo - SP: Contexto, 2019. NETTO, José Paulo. Introdução ao estudo do método de Marx. 1. ed. 4 reimp. São Paulo - SP: Editora xpressão Popular, 2015.

QUAINI, Massimo. Marxismo e geografia. Rio de Janeiro - RJ: Paz e Terra, 2002.

SANTOS, Milton. Por uma Nova Geografia: Da crítica da Geografia a uma Geografia Crítica. 6 ed. 2. Reimp. São Paulo - SP: Editora da Universidade de São Paulo, 2012.

SANTOS, Milton. Metamorfoses do espaço habitado: Fundamentos Teórico e Metodológico da Geografia. 6. Ed. 2. Reimp. São Paulo - SP: Editora da Universidade Federal de São Paulo, 2014.

TRIVIÑOS, Augusto Nibaldo Silva. Introdução à Pesquisa em Ciências Sociais: a pesquisa qualitativa em educação. São Paulo: Editora Atlas, 1987. 